\section{Conversion of Dorsal from an activator to a repressor by the global corepressor Groucho}

\author{
Todd Dubnicoff,, $1,4,5$ Scott A. Valentine, ${ }^{1}$ Guoqing \\ Chen, ${ }^{1}$ Tao Shi, ${ }^{1}$ Judith A. Lengyel, ${ }^{2,4}$ Ze'ev \\ Paroush, ${ }^{3}$ and Albert J. Courey ${ }^{1,4,6}$ \\ ${ }^{1}$ Department of Chemistry and Biochemistry, ${ }^{2}$ Department of \\ Molecular, Cell, and Developmental Biology, ${ }^{4} \mathrm{M}$ olecular \\ Biology Institute, University of California at Los Angeles, LoS \\ Angeles, California 90095 USA; ${ }^{3}$ Department of Biochemistry, \\ The Hebrew University-Hadassah Medical School, \\ Jerusalem 91120, Israel
}

The Dorsal morphogen acts as both an activator and a repressor of transcription in the D rosophila embryo to regulate the expression of dorsal/ventral patteming genes. Circumstantial evidence has suggested that Dorsal is an intrinsic activator and that additional factors (corepressors) convert it into a repressor. These corepressors, however, have previously eluded definitive identification. We show here, via the analysis of embryos lacking the matemally encoded Groucho corepressor and via protein-binding assays, that recruitment of Groucho to the template by protein:protein interactions is required for the conversion of Dorsal from an activator to a repressor. Groucho is therefore a critical component of the dorsal/ventral patterning system.

Received August 26, 1997; revised version accepted September 4, 1997.

Dorsal/ventral pattern formation in the Drosophila embryo is initiated by a nuclear concentration gradient of the maternally expressed Dorsal protein, a rel family transcription factor (for review, see Courey and Huang 1995). Dorsal regulates the spatially restricted expression of zygotically active dorsal-ventral patterning genes by acting as both a transcriptional activator and repressor. In ventral nuclei, peak levels of Dorsal protein activate transcription of the mesoderm determining genes, twist (twi) and snail (sna). In these same ventral nuclei, Dorsal protein also represses transcription of the dorsal fate determining genes, decapentaplegic (dpp) and zerknüllt (zen).

Transcriptional activation by Dorsal is mediated by enhancers termed ventral activation regions (VARs), whereas transcriptional repression by Dorsal is mediated by silencers termed ventral repression regions (VRRs). VARs in twi and sna and VRRs in zen and dpp contain multiple Dorsal binding sites that are required for enhancer or silencer activity (for review, see Courey and Huang 1995). When Dorsal-binding sites in the zen VRR

[Key Words: dorsal; groucho; corepressor; Drosophila; pattern formation; embryogenesis]

5Present address: Tularik, Inc., South San Francisco, California 94080 USA.

'Corresponding author.

E-MAIL courey@chem.ucla.edu; FAX (310) 206-4038. are isol ated from their surrounding regulatory region and oligomerized, they mediate transcriptional activation (Jiang et al. 1992; Pan and Courey 1992). These results suggest that Dorsal is intrinsically a transcriptional activator and that its interaction with additional factors (termed corepressors) is required for repression. VRRs contain elements in addition to Dorsal-binding sites that are required for repression and that presumably function by recruiting corepressors via protein-DN A interactions (Jiang et al. 1993; Kirov et al. 1993; Huang et al. 1995). Multiple candidates for these DNA-bound corepressor proteins have been identified, including Dsp-1 (Lehming et al. 1994) and NTF-1 (Huang et al. 1995). However, definitive genetic evidence of a role for these factors in dorsal/ventral pattern formation is lacking.

The mechanism by which DNA-bound Dorsal and DN A-bound corepressors cooperate to bring about transcriptional repression is unknown. One possibility is that these factors work together to recruit additional corepressors to the template that are unable to bind DNA on their own. Indeed, many sequence-specific DNAbinding transcriptional repressors function in this manner. In yeast, for example, the Tup1/Ssn6 complex represses the transcription of many sets of genes through protein-protein interactions with DN A-bound repressor proteins such as $\alpha-2$ and Mig-1 (Keleher et al. 1992). In Drosophila and in vertebrates, Groucho (Gro) and Gro homologs repress the transcription of a wide variety of genes involved in multiple developmental processes (Paroush et al. 1994, 1997; Dehni et al. 1995). LikeTup1/ Ssn6, Gro does not bind to DNA on its own and is recruited to the template via interactions with various DNA-bound repressor proteins. In the previously characterized cases, the DNA-bound repressor proteins are members of the Hairy family of basic helix-loop-helix (bHLH) transcription factors and all contain conserved carboxy-terminal WRPW motifs that are both necessary and sufficient for binding interactions with Gro (Fisher et al. 1996). Both the Tup1 and the Gro proteins are members of a large and diverse family of proteins that contain WD repeat domains. These domains, which are thought to represent protein-protein interaction domains, are characterized by multi ple tandem repeats of a 40-amino-acid motif containing a conserved Trp-Asp (WD) di peptide residue ( $\mathrm{N}$ eer et al. 1994).

We show here that Dorsal can activate but not repress transcription in embryos lacking Gro activity. Furthermore, protein-protein interaction assays in vitro show that Dorsal and Gro can bind to one another directly, strongly suggesting that Dorsal helps to recruit Gro to the template where it can repress transcription. These studies represent the first definitive identification of a factor required for the conversion of Dorsal from an activator to a repressor and demonstrate that Gro is a critical component of the dorsal/ventral patterning system.

\section{Results and Discussion}

Gro is required for Dorsal-mediated ventral repression In a previous study, ventral furrow formation was found 
to be defective in embryos lacking wild-type maternal gro gene product (Paroush et al. 1994). One possible explanation for this gastrulation defect is the inappropriate expression of dorsal/ventral patterning genes. To determine what role Gro might have in the regulation of these genes, we used the ovo ${ }^{\mathrm{D}}$-FLP-FRT system to generate mosai c females contai ning gro germ-line clones (Paroush et al. 1997). The embryos obtained from these females are devoid of maternally contributed wild-type gro activity and are referred to as gromat-. For these experiments, we used fly stocks carrying either gro ${ }^{\mathrm{E} 48}$, a strong hypomorphic allele, or gro ${ }^{\mathrm{BX} 22}$, a null allele.

We first examined dpp and zen expression patterns in these gro ${ }^{\text {mat }}$ - embryos, because we reasoned that the reported transcriptional corepressor activity of Gro might play a role in the Dorsal-mediated ventral repression of dpp and zen. In wild-type embryos, zen and dpp transcripts are restricted to the termini and the dorsal $45 \%$ of the wild-type blastoderm embryo (Fig. 1A,D); in gromatembryos, however, the zen and dpp expression patterns show a dramatic ventral expansion. Whereas the gro E48mat- embryos still exhibit some residual dorsal/ ventral asymmetry in the zen and dpp expression patterns (Fig. 1B,E), a complete expansion resulting in near uniform expression is observed in the gro ${ }^{\mathrm{B} \times 22 \mathrm{mat}-} \mathrm{em}-$ bryos (Fig. 1C,F).

To determine whether the observed ventral expansion in zen expression is due to a direct requirement for Gro in Dorsal-mediated repression, we examined the expression pattern of a zen VRR/lacZ transgene in gro ${ }^{\text {mat- }}$ embryos. For this experiment, wild-type females or femal es containing gro ${ }^{\mathrm{E} 8 \mathrm{mat}}$ - germ-line clones were crossed with mal es transgenic for P-el ement constructs containing a lacZ transgene under the control of the evenskipped (eve) minimal stripe 2 enhancer [M SE (Small et al. 1992)]. By itself, the MSE directs a single transverse stripe of gene expression in the syncytial blastoderm embryo extending from $\sim 75 \%$ to $\sim 55 \%$ egg length (Fig. $2 \mathrm{~A}$ ). Upstream of the MSE, two copies of a minimal 180-bp zen VRR were inserted. This module contains three Dorsal-binding sites and three evolutionarily conserved ATrich elements. The three Dorsal-binding sites and two of the three AT-rich elements have been found to contribute to the ability of the VRR to repress transcription ventrally (Ip et al. 1991; Jiang et al. 1993; Kirov et al. 1993). In a wild-type background, insertion of the VRR upstream of the MSE results in repression of the syncytial blastoderm stage stripe on the ventral side of the embryo (Fig. 2B; Jiang et al. 1993).

The effects of introducing the eve stripe 2 transgene into gro ${ }^{\text {E48mat }-~ e m b r y o s ~ a r e ~ c o m p l e x, ~ p r o b a b l y ~ o w i n g ~ t o ~}$ roles of gro in anterior/posterior (Paroush et al. 1994, 1997), as well as dorsal/ventral, pattern formation. In early syncytial blastoderm (nuclear cycle 11-12) gro ${ }^{\text {48mat- }}$ embryos (Fig. 2C), the anterior stripe seen in wild-type embryos is replaced by a broad anterior domain that extends to the anterior pole of the embryo. The posteri or border of the domain is somewhat variable in position but is usually between $70 \%$ and 55\% egg length. This border is al so more graded than the posterior border of the wild-type MSE-driven stripe. In somewhat later embryos (nuclear cycle 13), the expression at the anterior pole of the embryo is lost and the posterior border of the domain becomes better defined (Fig. 2D). Regardless of al terations in the anterior/posterior pattern of expression, however, we see little or no ventral repression of the VRR/MSE reporter in the gro ${ }^{\mathrm{E} 48 m a t-}$ background. In fact, the broad anterior domain in the nuclear cycle 11-12 embryos is usually accompanied by expression across the entire ventral surface of the embryo (Fig. 2C). This is probably due to the ability of the VRR to direct Dorsal-dependent ventral activation in the absence of corepressor activity, as inactivation of the AT-2 corepression element by mutagenesis results in very similar ventral expression of the lacZ reporter (Jiang et al. 1993). These results strongly suggest that Gro is a transcriptional corepressor that is essential for the conversion of Dorsal from a transcriptional activator into a transcriptional repressor.

Gro is not required for the spatially regulated expression of genes that are activated by Dorsal

To determine whether Gro has a role in ventral activation, we examined twi expression in embryos lacking maternal Gro and found that these embryos still express twi in a ventral-specific pattern (Fig. $1 \mathrm{H}, \mathrm{I}$ ). Similarly, Gro is not required for the ventral-specific expression of sna (data not shown). These results demonstrate that Gro is not required for Dorsal-mediated ventral activation. Furthermore, they imply that the gradient of Dorsal
Figure 1. Maternal gro requirement for dorsal-mediated ventral repression. Optical sagittal sections of nucl ear cycle 13 embryos are shown in A-F, with dorsal side up and anterior to the left. Ventral views of nuclear cycle 13 embryos are shown in G-I, with anterior to the left. mRN A expression patterns are reveal ed by whole mount in situ hybridization. dpp expression pattern in wild-type (A), gro $^{\mathrm{E}^{48 m a t}-}(\mathrm{B})$ and gro $^{\mathrm{B} \times 22 \mathrm{mat}-}$ blastoderm embryos $(\mathrm{C})$. zen expression pattern in wild-type (D), gro ${ }^{\mathrm{E} 48 m a t-}(\mathrm{E})$, and gro $^{\mathrm{B} \times 22-}(\mathrm{F})$ blastoderm embryos. twi expression pattern in wild-type $(\mathrm{G})$, gro ${ }^{\mathrm{E} 48-}(\mathrm{H})$, and $\operatorname{gro}^{\mathrm{B} \times 22-}(\mathrm{I})$ blastoderm embryos. 


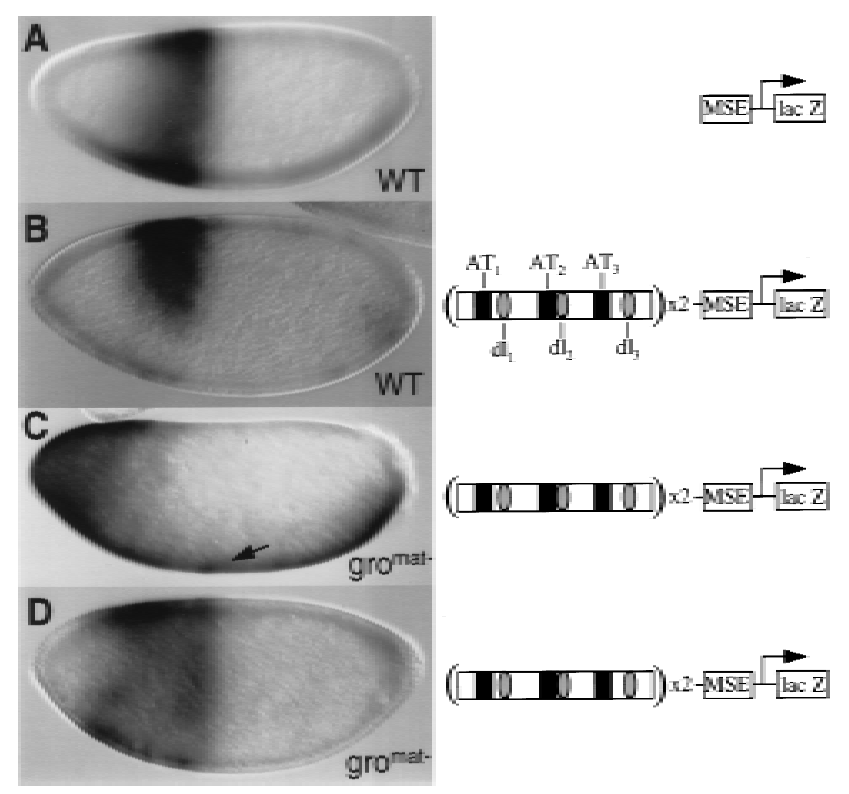

Figure 2. Maternal gro is required for the ventral repression directed by the minimal zen VRR. Wild-type nuclear cycle 13 embryos (A,B) or gro nuclear cycle 11 (C) or nuclear cycle 13 (D) embryos containing transgenic P-element constructs (right), which are essentially identical to those used previously (Jiang et al. 1993). Lateral views of syncytial blastoderm embryos are shown. IacZ mRN A was detected by whole mount in situ hybridization. The construct in A contains the minimal eve-stripe 2 enhancer (M SE) driving lacZ expression (M SE-lacZ); the constructs in B-D contain two copies of the minimal 180-bp zen VRR upstream of the MSE (VRR-MSE). Black boxes represent the AT-rich corepression el ements; shaded ovals represent Dorsal-binding sites. The arrow in C shows the VRR-directed expression of IacZ across the entire ventral surface.

nuclear local ization must be essential ly intact in gro ${ }^{\text {mat- }}$ embryos. Surprisingly, we observe a small ventral expansion of the twi ventral stripe in gro ${ }^{\mathrm{B} \times 22 \mathrm{mat}-}$ embryos. In both the wild-type (Fig. 1G) and gro ${ }^{\text {48mat }-~}(\mathrm{Fig} .1 \mathrm{H})$ embryos, the twi ventral stripe of expression is 18-20 cells wide but expands to 20-24 cell widths in the gro ${ }^{\mathrm{B} 22 \mathrm{mat}-}$ embryos (Fig. 11). Given that the expression of ventrol aterally expressed genes is significantly reduced in gromat- embryos (see below), this expanded twi expression suggests that the lateral borders of twi expression coul $d$ be repressed by zygotical ly active, ventrolaterally expressed genes.

Dorsal is also required for the activation of genes normally expressed in the ventrolateral neuroectodermal anlage (Ip et al. 1992b; Gonzalez-Crespo and Levine 1993). Thus, to further test the idea that Gro is dispensable for Dorsal-mediated activation, we examined the effect of reduced Gro activity on the expression of the three neuroectodermal genes single-minded (sim), rhomboid (rho), and short gastrulation (sog). As summarized be- low, in each case, we observed a weakening of expression, and in some cases, we al so observed a change in the anterior/posterior expression pattern in gro ${ }^{\text {mat- }}$ embryos. However, no changes were observed in the dorsal/ventral positioning of the expression domains, implying that Gro does not play a direct role in the Dorsal-mediated activation of neuroectodermal genes.

In wild-type blastoderm embryos, sim is expressed as a single row of cells along each side of the embryo (Fig. $3 A$ ). This row of cells constitutes the boundary between the presumptive mesoderm and presumptive neuroectoderm (Thomas et al. 1988) and gives rise to the mesectoderm. In gro ${ }^{\text {E48mat- }}$ embryos, the sim stripes are barely evident in the anterior $75 \%$ of the embryo, with weak expression remaining at the posterior end of the embryo (Fig. 3B). In gro ${ }^{\mathrm{B} \times 22 m a t-}$ embryos the stripes are just barely detectable (Fig. 3C). In wild-type embryos, rho is expressed as a pair of broad lateral stripes 8-10 cells wide (Fig. 3D) (Bier et al. 1990); in gro ${ }^{\text {E48mat- }}$ embryos, these stripes extend slightly more anteriorly, but are weaker posteriorly, becoming undetectable at $\sim 30 \%$ egg length (Fig. 3E). Consistent with the sim results, rho transcripts are even less abundant in gro ${ }^{\mathrm{B} 222 \mathrm{mat}^{-}}$embryos (Fig. 3F). In wild-type blastoderm embryos, the bilateral expression domains of sog, which label the entire neuroectoderm, are 14-16 cells wide and display sharp anteriorposterior and dorsal-ventral limits (Fig. 3G) (Francois et al. 1994). In a gro E48mat- background, however, the sog stripes lose their sharp borders of expression (Fig. 3H). The effects on sog expression are stronger in a gro $^{\text {BX22mat- }}$ background (Fig. 31).

The activation of genes expressed in the neuroectodermal anlage is thought to depend on synergistic interactions between Dorsal and other transcription factors (Gonzalez-Crespo and Levine 1993; Jiang and Levine 1993; Shirokawa and Courey 1997). As Gro is not re quired for Dorsal-mediated activation, it is not surprising that the dorsal/ventral positions of the sim, rho, and

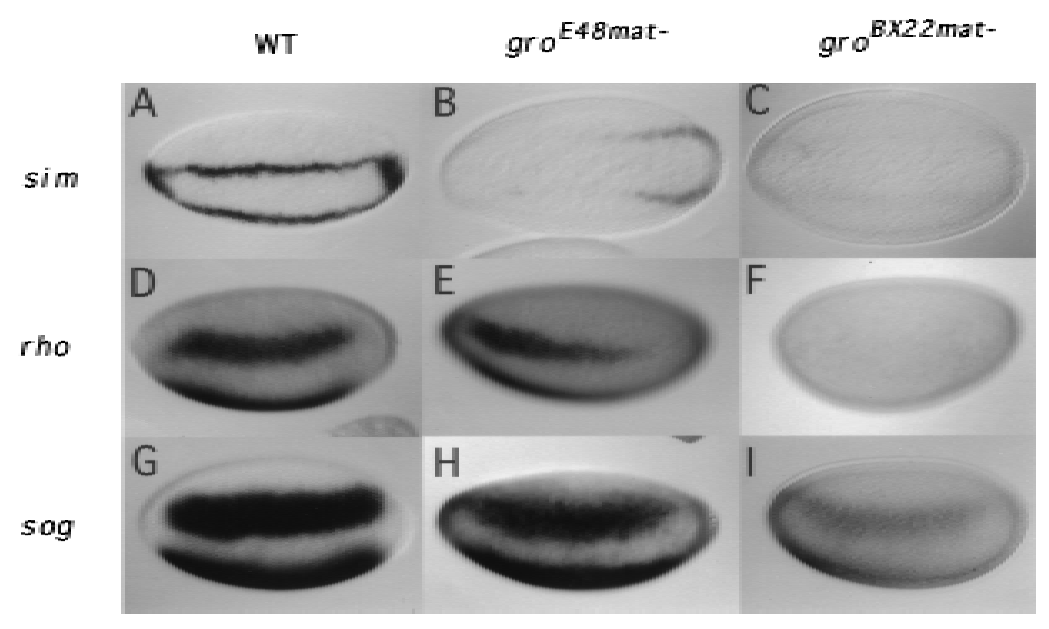

Figure 3. Reduced sim, rho, and sog expression in gromat- embryos. Ventrolateral $(A, D-I)$ or ventral $(B, C)$ views of nuclear cycle 13 embryos. sim expression pattern in wild-type $(A)$, gro ${ }^{\mathrm{E} 48 m a t}-(B)$, and gro ${ }^{B \times 22 m a t}-(C)$ embryos. rho expression pattern in wild-type (D), gro ${ }^{\mathrm{E} 48 \mathrm{mat}-}(\mathrm{E})$, and gro ${ }^{\mathrm{BX} 22 \mathrm{mat}-}(\mathrm{F})$ embryos. sog expression pattern in wild-type $(\mathrm{G})$, gro g48mat- $^{\mathrm{E}}(\mathrm{H})$, and gro ${ }^{\mathrm{B} \times 22 \mathrm{mat}-}(\mathrm{I})$ embryos. 
sog expression domains are not al tered by the absence of maternal Gro. The reduction in the expression level of ventrolateral ly expressed genes may be a secondary consequence of the ventrally expanded expression of $d p p$, which is known to prevent cells from adopting the ventral ectodermal fate (Ferguson and Anderson 1992; Biehs et al. 1996). Interestingly, ectopic expression of dpp in wild-type embryos leads to a repressi on of rho expression very similar to that observed here [cf. Fig. $3 \mathrm{E}$ in this paper to Fig. 2C in Biehs et al. (1996)].

Sog and Dpp proteins are thought to work in an antagonistic way to control the choice between neuroectodermal and dorsal ectodermal fates (Holley et al. 1995; Biehs et al. 1996). As currently understood, this antagonism consists of a blocking of Dpp activity by its interaction with Sog (Piccolo et al. 1996). Our results, showing diminished sog expression levels in embryos in which dpp expression is expanded, suggest an additional dimension to Sog/Dpp antagonism: The dpp pathway may function to negatively regulate sog at the transcriptional level. We cannot, however, rule out the possibility that the diminished expression of sog and other neuroectodermal and mesectodermal genes is due to the depression of zen or other unknown dorsal ectoderm-specific genes rather than to the derepression of $\mathrm{dpp}$.

Dorsal may help to recruit Gro to the template via a direct protein-protein interaction

Genetic and biochemical analysis suggests that Gro can be recruited to target genes through physical interactions with DN A-bound Hairy-related bHLH proteins (Paroush et al. 1994; Fisher et al. 1996). To investigate whether similar protein-protein interactions exist for Gro-dependent, Dorsal-mediated repression, we performed proteinprotein binding assays using glutathione S-transferase (GST) fusion proteins immobilized on glutathione-derivatized agarose beads (GST pulldown assays). The as- says reveal a binding interaction between ${ }^{35} \mathrm{~S}$-labeled Dorsal and GST-Gro (Fig. 4A, lane 11). The converse assay, testing for an interaction between ${ }^{35} \mathrm{~S}$-label ed Gro and GST -Dorsal, al so demonstrates in vitro binding (Fig. 4A, lane 9). Several control experiments were carried out to confirm the specificity of these interactions. No signals were detected when ${ }^{35} \mathrm{~S}$-label ed luciferase, an unrelated protein, was used in the pul Idown assay with either GST-Dorsal or GST-Gro (Fig. 4A, lanes 8,10 ). In addition, GST al one showed no interactions with either ${ }^{35} \mathrm{~S}$ label ed Gro or ${ }^{35} \mathrm{~S}$-label ed Dorsal (Fig. 4A, lanes 5,7), nor did ${ }^{35}$ S-l abel ed Gro interact with GST-T wi (Fig. 4A, Iane 14). Consistent with a previous report, we observed an interaction between Dorsal and GST-Twi (Fig. 4A, lane 13); this interaction is thought to account for the ability of these two factors to synergistically activate transcription (Shirokawa and Courey 1997).

As an independent means of verifying the binding interaction between Dorsal and Gro, we carried out immunoprecipation experiments with crude extracts of Sf9 cells harboring baculovirus expression vectors encoding Dorsal and/or epitope-tagged Gro. Antibodies against the epitope tag were found to immunoprecipate Dorsal protein in the presence (Fig. 4B, lane 8), but not in the absence (lane 4) of epitope-tagged Gro.

If the Dorsal:Gro interaction detected in the GST pulldown assay is required for Dorsal-mediated repression, we expect the interaction to be maintained when we truncate Dorsal by removing sequences carboxy-terminal to the rel homology domain. This hypothesis is based on previous studies demonstrating that a mutant Dorsal protein containing only the rel homology domain was still able to repress transcription in vivo (Isoda et al. 1992). In agreement with these genetic data, ${ }^{35}$ S-labeled Dorsal 379 (a truncated form of Dorsal containing only the amino-terminal 379 amino acids) bound to GST -Gro (Fig. 4A, lane 12).

A
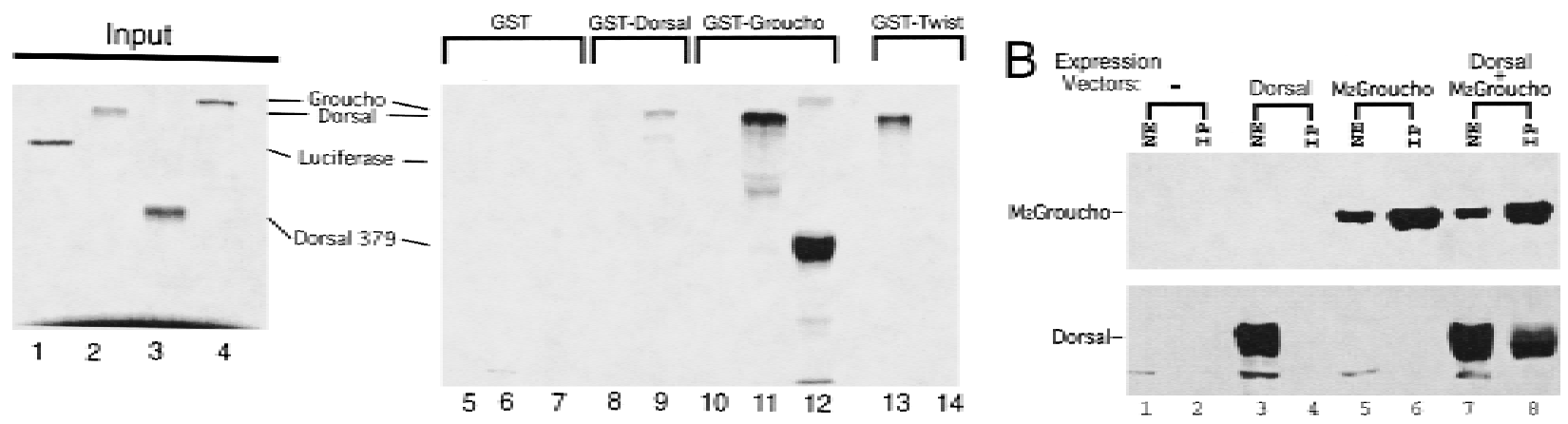

Figure 4. Binding of Dorsal to Gro. (A) GST fusion proteins purified and immobilized on gl utathione agarose beads were incubated with in vitro translated, ${ }^{35} \mathrm{~S}$-labeled proteins. After extensive washing, bound proteins were eluted from the beads and analyzed by SDS-PAGE and autoradiography. (Lanes 1-4) 1/10th the amount of input ${ }^{35}$ S-labeled proteins used in the binding assay; (lanes 5-14) the ${ }^{35} \mathrm{~S}$-label ed proteins after binding to the indicated immobilized GST fusions proteins. The ${ }^{35} \mathrm{~S}$-label ed proteins are luciferase (lanes 1,8,10), Dorsal (Ianes 2,5,11,13), Dorsal 379 (Ianes 3,6,12), and Gro (lanes 4,7,9,14). (B) Coimmunoprecipitation experiments: Sf9 cells were infected with an empty baculovirus expression vector (lanes 1,2), a vector expressing Dorsal (lanes 3,4), a vector expressing M 2-tagged Gro (lanes 5,6), or vectors expressing D orsal and M 2-tagged Gro (lanes 7,8). (Lanes 1,3,5,7) crude nucl ear extracts of infected cells; (lanes $2,4,6,8$ ) immunoprecipitates obtained using the anti-M 2 antibody. Immunoblots were probed with anti-M2 (top) or anti-Dorsal (bottom) antibodies. 
Our finding that Gro can bind to Dorsal in vitro points toward a role for direct Dorsal-Gro interactions in the recruitment of Gro to the template where it functions to repress the expression of dorsal ectoderm-specific genes such as zen and dpp. Although binding between $\mathrm{Gro}$ and Dorsal is likely to facilitate the recruitment of Gro, this interaction is unlikely to be sufficient for Gro recruitment in vivo. We arrive at this conclusion because isolated Dorsal-binding sites direct ventral activation, whereas ventral repression requi res additional repression elements in the proximity of the Dorsal-binding sites (for review, see Courey and Huang 1995). These additional elements are presumably recognized by proteins that help to convert nearby DNA-bound Dorsal from an activator into a repressor (Lehming et al . 1994; Huang et al. 1995). Perhaps the observed in vitro binding interaction between Dorsal and Gro is too weak to allow Dorsal protein to efficiently recruit Gro to the DNA template in vivo without assistance from DNA-bound corepressor proteins. The DNA-bound corepressor proteins could interact with Dorsal to increase its affinity for Gro or they could contact Gro directly to stabilize the association of Gro with Dorsal.

Unlike other proteins known to bind Gro (Paroush et al. 1994; Fisher et al. 1996), Dorsal does not contain a WRPW motif. Similarly to the WD repeat domains in Tup1, the WD repeat domains in Gro may serve as multivalent protein interaction domains capable of binding to a wide variety of proteins.

Gro plays multiple roles in the patterning of the blastoderm embryo

In addition to the role in dorsal/ventral pattern formation demonstrated here, Gro plays multiple roles in anterior/posterior pattern formation (Paroush et al. 1994, 1997). As suggested by the severely defective body plan in gromat- embryos, this corepressor appears to be required for nearly all patterning of the blastoderm embryo. For example, Gro plays an important role in the function of the Torso-dependent terminal patterning system. In this system, expression of the tailless tIl gene is restricted to the termini of the embryo by repression elements termed Torso response elements. Repression by these elements is alleviated by the terminal specific activation of the Torso receptor tyrosine kinase pathway (Liaw et al. 1995). The activity of the Torso response elements is largely dependent on Gro, as the elimination of maternal Gro activity results in greatly expanded tII expression (Paroush et al. 1997). Previous studies revealed that mutations that result in the uniform activation of Torso result in the uniform expression of dpp and zen in addition to tII (Rusch and Levine 1994). Thus, for zygotically active genes of both the dorsal/ventral and terminal patterning systems, the activation of Torso has consequences similar to those resulting from the inactivation of Gro, that is, the loss of repression. These findings suggest that the Torso-activated protein phosphorylation cascade may well function by inactivating Gro, perhaps by modifying Gro itself or a critical Gro-interacting factor.

\section{The mechanism of repression by Gro}

Because Dorsal-dependent silencers can inactivate heterologous enhancers at a distance and in an orientationindependent manner (I p et al. 1991; Huang et al. 1993), the findings presented here strongly suggest that Gro mediates a form of long-range repression. This conclusion is consistent with a previous study showing that another Gro-dependent repressor, namely Hairy, also functions as a long-range repressor (Barolo and Levine 1997). Other modes of transcriptional repression, such as quenching (Gray and Levine 1996), are likely to function independently of Gro.

What mechanisms does Gro employ to carry out its silencing function? Given the sequence and functional homologies with the yeast global corepressor Tup1, it is likely that Gro and Tupl repress transcription by a common mechanism. Silencing by Tup1 may occur via changes in chromatin structure. In Tupl mutants, genes normally silenced by T upl not only become derepressed, but their promoter regions show disturbances in nucleosome stability and positioning (Cooper et al. 1994). Furthermore, a repression domain of Tup1 recentl y has been shown to bind directly to histones $\mathrm{H} 3$ and H4 (Edmondson et al. 1996). In addition to contacting chromatin, Tup1 may directly contact the general transcriptional machinery (Wahi and Johnson 1995; Song et al. 1996). By anal ogy, perhaps Gro directl y contacts the basal machinery to block transcriptional initiation.

\section{Materials and methods}

Analysis of embryos derived from germ-line clones gro germ-line clones were generated as described previously (Paroush et al. 1997). Embryos were analyzed by whole mount in situ hybridization (Tautz and Pfeifle 1989).

Protein-protein interaction assays

Bacterial expression of GST fusion proteins utilized pGex expression vectors (Pharmacia). GST fusion proteins were expressed in Escherichia coli and purified as described previously (Smith and Corcoran 1990). GST pull-down assays were carried out as described previously (Smith and Corcoran 1990). Approximately $1-5 \mu \mathrm{g}$ of the indicated GST fusion protein (30 $\mu \mathrm{g}$ of GST protein) immobilized on $30 \mu \mathrm{l}$ of glutathione-agarose beads was washed two times with $1 \mathrm{ml}$ of HEM NK buffer $(40 \mathrm{~mm}$ HEPES at $\mathrm{pH}$ 7.5, $5 \mathrm{~mm} \mathrm{MgCl}_{2}, 0.2 \mathrm{~mm}$ EDTA, $1 \mathrm{~mm}$ DTT, 0.5\% NP-40, $0.1 \mathrm{~m}$ $\mathrm{KCl}$ ). The beads were left in $0.6 \mathrm{ml}$ of HEM NK after the final wash and then were incubated with $20 \mu \mathrm{l}$ of the indicated ${ }^{35}$ S-labeled protein for 2 $\mathrm{hr}$ at $4^{\circ} \mathrm{C}$ with gentle mixing. The beads were then washed at least four times with HEM N K buffer. Bound radiolabel ed proteins were el uted with $30 \mu \mathrm{l}$ of SDS-sample buffer, boiled for $5 \mathrm{~min}$, and resolved by SDS-PAGE.

The recombinant baculovirus used in the expression of Dorsal was described previously (Shirokawa and Courey 1997). The recombinant baculovirus expressing the M 2 epitope-tagged Gro was kindly provided by R. Tjian (University of California, Berkeley). Baculovirus-infected cells were harvested after $40 \mathrm{hr}$, and nuclear extracts were prepared as described previously (Shirokawa and Courey 1997). For coimmunoprecipitation assays, $200 \mu \mathrm{l}$ of nuclear extract was immunoprecipitated with $20 \mu \mathrm{l}$ of prewashed anti-M2 affinity gel (Kodak). The precipitates were then washed three times with buffer D' (20 mm HEPES at pH 7.9, $50 \mathrm{~mm}$ $\mathrm{NaCl}, 1 \mathrm{~mm}$ EDTA, 0.1\% NP-40, 10\% glycerol, $1 \mathrm{~mm}$ DTT, $0.5 \mathrm{~mm}$ PM SF) and then three more times with buffer $D^{\prime}$ containing $0.4 \mathrm{M} \mathrm{NaCl}$. They were then subjected to $6 \%$ SDS-PAGE and subsequently immuno- 
blotted. The immunoblots were probed with anti-M2 monoclonal antibody (Kodak) or anti-Dorsal polyclonal antibody.

\section{Acknowledgments}

We thank Utpal Banerjee for his helpful comments on the manuscript. This work was supported by $\mathrm{N}$ ational Institutes of Health (NIH) grant GM 44522 to A.J.C. and by NIH grant GM 51270 to J.A.L. and A.J.C. Z.P. is supported by a Research Career Devel opment A ward of the Israel Cancer Research Fund and by a research grant from the Israel Academy of Sciences and Humanities.

The publication costs of this article were defrayed in part by payment of page charges. This article must therefore be hereby marked "advertisement" in accordance with 18 USC section 1734 solely to indicate this fact.

\section{References}

Barolo, S. and M. Levine. 1997. hairy mediates dominant repression in the Drosophila embryo. EMBO J. 16: 2883-2891.

Biehs, B., V. Francois, and E. Bier. 1996. The Drosophila short gastrulation gene prevents $\mathrm{Dpp}$ from autoactivating and suppressing neurogenesis in the neuroectoderm. Genes \& Dev. 10: 2922-2934.

Bier, E., L.Y. Jan, and Y.N. Jan. 1990. rhomboid, a gene required for dorsoventral axis establishment and peripheral nervous system de velopment in Drosophila melanogaster [published erratum appears in Genes \& Dev. 1990 4: 680-681] Genes \& Dev. 4: 190-203.

Cooper, J.P., S.Y. Roth, and R.T. Simpson. 1994. The global transcriptional regulators, SSN 6 and TUP1, play distinct roles in the establishment of a repressive chromatin structure. Genes \& Dev. 8: 14001410.

Courey, A.J. and J. Huang. 1995. The establishment and interpretation of transcription factor gradients in the Drosophila embryo. Biochim. Biophys. Acta 1261: 1-18.

Dehni, G., Y. Liu, J. Husain, and S. Stifani. 1995. TLE expression corre lates with mouse embryonic segmentation, neurogenesis, and epithelial determination. Mech. Dev. 53: 369-381.

Edmondson, D.G., M.M. Smith, and S.Y. Roth. 1996. Repression domain of the yeast gl obal repressor Tup1 interacts directly with histones $\mathrm{H} 3$ and H4. Genes \& Dev. 10: 1247-1259.

Ferguson, E.L. and K.V. Anderson. 1992. decapentaplegic acts as a morphogen to organize dorsal-ventral pattern in the Drosophila embryo. Cell 71: 451-461.

Fisher, A.L., S. Ohsako, and M. Caudy. 1996. The WRPW motif of the hairy-related basic helix-loop-helix repressor proteins acts as a 4amino-acid transcription repression and protein-protein interaction domain. Mol. Cell. Biol. 16: 2670-2677.

Francois, V., M. Solloway, J.W. O'N eill, J. Emery, and E. Bier. 1994. Dorsal-ventral patterning of the Drosophila embryo depends on a putative negative growth factor encoded by the short gastrulation gene. Genes \& Dev. 8: 2602-2616.

Gonzalez-Crespo, S. and M. Levine. 1993. Interactions between Dorsal and helix-loop-helix proteins initiate the differentiation of the embryonic mesoderm and neuroectoderm in Drosophila. Genes \& Dev. 7: 1703-1713.

Gray, S. and M. Levine. 1996. Transcriptional repression in development. Curr. O pin. Cell Biol. 8: 358-364.

Holley, S.A., P.D. Jackson, Y. Sasai, B. Lu, E.M. De Robertis, F.M. Hoffmann, and E.L. Ferguson. 1995. A conserved system for dorsal-ventral patterning in insects and vertebrates involving sog and chordin. $\mathrm{Na}$ ture 376: 249-253

Huang, J., D.H. Schwyter, J.M. Shirokawa, and A.J. Courey. 1993. The interplay between multiple enhancer and silencer elements defines the pattern of Decapentaplegic expression. Genes \& Dev. 7: 694-704.

Huang, J.D., T. Dubnicoff, G.J. Liaw, Y. Bai, S.A. Valentine, J.M. Shirokawa, J.A. Lengyel, and A.J. Courey. 1995. Binding sites for transcription factor NTF-1/Elf-1 contribute to the ventral repression of decapentaplegic. Genes \& Dev. 9: 3177-3189.

Ip, Y.T., R. Kraut, M. Levine, and C.A. Rushlow. 1991. The dorsal morphogen is a sequence-specific DNA-binding protein that interacts with a long-range repression element in Drosophila. Cell 64: 439446.

Ip, Y.T., R.E. Park, D. Kosman, E. Bier, and M. Levine. 1992. The dorsal gradient morphogen regulates stripes of rhomboid expression in the presumptive neuroectoderm of the Drosophila embryo. Genes \& Dev. 6: 1728-1739.

Isoda, K., S. Roth, and C. N üsslein-Volhard. 1992. The functional domains of the Drosophila morphogen Dorsal-Evidence from the analysis of mutants. Genes \& Dev. 6: 619-630.

Jiang, J., H. Cai, Q. Zhou, and M. Levine. 1993. Conversion of a Dorsaldependent silencer into an enhancer-Evidence for Dorsal corepressors. EMBO J. 12: 3201-3209.

Jiang, J. and M. Levine. 1993. Binding affinities and cooperative interactions with bHLH activators delimit threshold responses to the Dorsal gradient morphogen. Cell 72: 741-752.

Jiang, J., C.A. Rushlow, Q. Zhou, S. Small, and M. Levine. 1992. Individual dorsal morphogen binding sites mediate activation and repression in the Drosophila embryo. EMBO J. 11: 3147-3154.

Keleher, C.A., M.J. Redd, J. Schultz, M. Carlson, and A.D. Johnson. 1992. Ssn6-Tup1 is a general repressor of transcription in yeast. Cel 68: 709-719.

Kirov, N., L. Zhelnin, J. Shah, and C. Rushlow. 1993. Conversion of a silencer into an enhancer-Evidence for a co-repressor in Dorsal-mediated repression in Drosophila. EMBO J. 12: 3193-3199.

Lehming, N., D. Thanos, J.M. Brickman, J. Ma, T. Maniatis, and M. Ptashne. 1994. An HMG-like protein that can switch a transcriptional activator to a repressor. Nature 371: 175-179.

Liaw, G.J., K.M. Rudol ph, J.D. Huang, T. Dubnicoff, A.J. Courey, and J.A Lengyel. 1995. The torso response element binds GAGA and NTF$1 /$ Elf-1, and regulates tailless by relief of repression. Genes $\&$ Dev. 9: 3163-3176.

Neer, E.J., C.J. Schmidt, R. Nambudripad, and T.F. Smith. 1994. The ancient regulatory-protein family of WD-repeat proteins [published erratum appears in Nature 1994, 371: 812]. Nature 371 297-300.

Pan, D. and A.J. Courey. 1992. The same dorsal binding site mediates both activation and repression in a context-dependent manner EMBO J. 11: 1837-1842.

Paroush, Z., R. Finley, Jr., T. Kidd, S.M. Wainwright, P.W. Ingham, R. Brent, and D. Ish-Horowicz. 1994. Groucho is required for Drosophila neurogenesis, segmentation, and sex determination and interacts directly with hairy-related bHLH proteins. Cell 79: 805-815.

Paroush, Z., S.M. Wainwright, and D. Ish-Horowicz. 1997. Relief of Groucho repression by torso signalling in Drosophila terminal patterning. Development 124: 3827-3834.

Piccolo, S., Y. Sasai, B. Lu, and E.M. De Robertis. 1996. Dorsoventral patterning in Xenopus: Inhibition of ventral signals by direct binding of chordin to BM P-4. Cell 86: 589-598.

Rusch, J. and M. Levine. 1994. Regulation of the dorsal morphogen by the Toll and torso signaling pathways: A receptor tyrosine kinase selectively masks transcriptional repression. Genes \& Dev. 8: 1247-1257.

Shirokawa, J.M. and A.J. Courey. 1997. A direct contact between the Dorsal rel homology Dopmain and Twist may mediate transcriptional synergy. Mol. Cell. Biol. 17: 3345-3355.

Small, S., A. Blair, and M. Levine. 1992. Regulation of even-skipped Stripe-2 in the Drosophila embryo. EMBO J. 11: 4047-4057.

Smith, D. and L. Corcoran. 1990. Expression and purification of glutathione-S-transferase fusion proteins. In Current protocols in molecular biology (ed. F.M. Ausubel, R. Brent, R.E. Kingston, D.D. Moore, J.G. Seidman, J.A. Smith, and K. Struhl), pp. 16.7.1-16.7.8. John Wiley, N ew York, NY.

Song, W., I. Treich, N. Qian, S. Kuchin, and M. Carlson. 1996. SSN genes that affect transcriptional repression in Saccharomyces cerevisiae encode SIN 4, ROX3, and SRB proteins associated with RN A polymerase II. Mol. Cell. Biol. 16: 115-120.

Tautz, D. and C. Pfeifle. 1989. A non-radioactive in situ hybridization method for the locational of specific RNAs in Drosophila embryos reveals translational control of the segmentation gene hunchback. Chromosome 98: 81-85.

Thomas, J.B., S.T. Crews, and C.S. Goodman. 1988. M olecular genetics of the single-minded locus: A gene involved in the development of the Drosophila nervous system. Cell 52: 133-141.

Wahi, M. and A.D. Johnson. 1995. Identification of genes required for al pha 2 repression in Saccharomyces cerevisiae. Genetics 140: 79-90. 


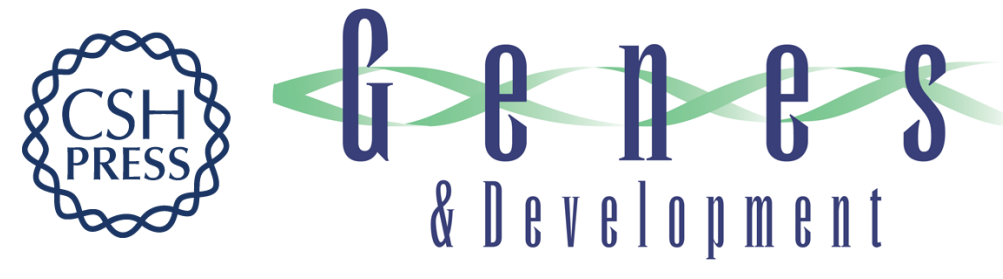

\section{Conversion of Dorsal from an activator to a repressor by the global corepressor Groucho}

Todd Dubnicoff, Scott A. Valentine, Guoqing Chen, et al.

Genes Dev. 1997, 11:

Access the most recent version at doi:10.1101/gad.11.22.2952

References

This article cites 36 articles, 18 of which can be accessed free at: http://genesdev.cshlp.org/content/11/22/2952.full.html\#ref-list-1

License

Email Alerting

Receive free email alerts when new articles cite this article - sign up in the box at the top Service right corner of the article or click here.

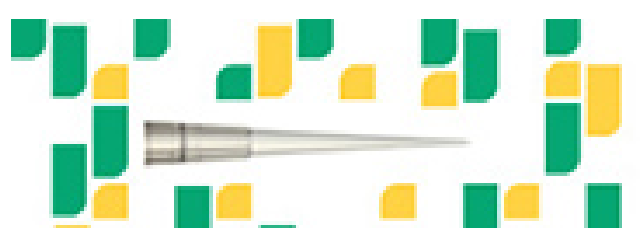

Focused on your science. 